\title{
Shared Decision Making in Residential Aged Care: A Framework Synthesis
}

\author{
Kaye Ervin'1, Irene Blackberry'1, Helen Haines² \\ ${ }^{1}$ LaTrobe University, John Richards Initiative, Albury Wodonga, Australia \\ ${ }^{2}$ University of Melbourne, Department of Rural Health, Shepparton, Victoria, Australia \\ Email: ervink@humehealth.org.au
}

How to cite this paper: Ervin, K., Blackberry, I. and Haines, H. (2017) Shared Decision Making in Residential Aged Care: A Framework Synthesis. Open Journal of Nursing, 7, 814-837. https://doi.org/10.4236/ojn.2017.77062

Received: June 6, 2017

Accepted: July 24, 2017

Published: July 27, 2017

Copyright (c) 2017 by authors and Scientific Research Publishing Inc. This work is licensed under the Creative Commons Attribution International License (CC BY 4.0).

http://creativecommons.org/licenses/by/4.0/

cc) (i) Open Access

\begin{abstract}
Very little is known about shared decision making (SDM) in residential aged care, despite world-wide policy and imperatives that encourage resident choice and autonomy. This paper provides a framework synthesis of SDM in residential aged care (RAC) and potential barriers and enablers to implement SDM utilising a theoretical framework of implementation. A review of the literature on SDM in RAC from 2005 to 2016 was undertaken, using MEDLINE (Ovid), CINAHL, PsychINFO and Scopus. The articles were synthesised by utilising an implementation theory framework to better understand what may facilitate or hinder the introduction of SDM. Eighteen studies were identified and analysed to determine barriers and enablers to SDM in RAC from the perspectives of staff, residents and relatives. A workplace culture of person-centred care and judicious use of research evidence are enablers of SDM. There is a potential need for additional resources, such as education for staff and families to enable implementation of SDM. Implementation of any health care intervention, including SDM, relies on many complex factors but these are predominantly related to capacity. Determining current uptake and readiness of RAC organisations, residents and their families to adopt SDM is an essential starting point.
\end{abstract}

\section{Keywords}

Narrative Synthesis, Shared Decision Making, Residential Aged Care, Implementation

\section{Introduction}

Shared decision making (SDM) brings clinicians and patients together about making shared decisions on patient's care, as opposed to clinicians making decisions on behalf of the patient [1]. SDM is considered the pinnacle of Person 
Centred Care (PCC) [2]. SDM integrates patient values, goals and concerns with the best available evidence about benefits, risks and uncertainties of treatment to achieve an option which is acceptable to both the patient and the clinician [3]. SDM is based on important moral, ethical and legal principles, and is recognised as important in developing a genuinely patient-centred health system [4]. The core of SDM is that individual self-determination and autonomy are desirable goals for patients [2].

There are no existing definitions of SDM specific to differing health care settings. In general, Coulter and Collins [5] describe three essential components of SDM:

- The patient is provided with current, unbiased evidence based information about potential treatment, care or support clarifying outcomes or uncertainties

- There is decision support counselling with a clinician to clarify options and patient preferences

- There is a robust system to record patient preferences, to communicate them to others and to execute the preferred choice.

SDM is poorly understood by clinicians [6] who, in addition, may not have a sufficient level of research literacy to fully understand evidence based findings from the literature [7], let alone translate those findings in a meaningful way in a patient encounter. Current research in SDM has been limited to measuring processes used by clinicians in patient/clinician dyads as well as focusing on patient perspectives of their involvement and satisfaction with the decision making process, or clinicians' opinions on SDM effectiveness [8].

Very little is known about SDM in residential aged care (RAC) settings, despite increasing emphasis on resident choice and autonomy in aged care reforms internationally [9] [10] [11]. Likewise knowledge specific to the implementation steps required successfully achieving SDM in the context of RAC is unknown. This is problematic given that the World Health Organization (WHO) advocates for a human rights approach for health and ageing including the right of a person to actively participate in decision making about their health care, as a basis for quality of care [12]. SDM is increasingly advocated in clinical guidelines and health care policy [3] [13] [14]-an imperative that health care providers cannot achieve without a greater understanding of the enablers and barriers to implementation.

\section{Design}

We synthesised the literature for current practices and processes for potential implementation of SDM in RAC from the perspective of staff, residents and resident's families. A narrative synthesis approach was utilised as opposed to a rigid systematic review. A systematic review uses strict criteria to summarize the evidence of studies and focuses on the effectiveness of an intervention. On the other hand, a narrative synthesis employs a textual approach to examine the heterogeneity of studies and population groups, while incorporating principles of a 
systematic review. Application of the strict criteria of a systematic review would have excluded relevant studies concerned with implementation of the phenomena under review. Hence, a narrative synthesis was better suited to describe the scope of the existing SDM concepts to describe implementation in practice.

Narrative synthesis enabled the interpretation of isolated research findings which used different research approaches. We used framework synthesis, described by Richie and Spencer [15], based on existing conceptual framework to identify a priori themes [16].

\subsection{Conceptual Framework}

Two frameworks were utilised for this review. Previously identified terms and the taxonomy and mapping of concepts [17] was utilised for the search strategy. The studies are described using this conceptual framework to show the relationship to SDM. The findings from this search are then synthesized using May's theory of implementation [18], to explain how the findings relate to clinical practice.

Embedding SDM as a new healthcare intervention within the usual clinical practice may be challenging. May [18] proposes implementation of a new intervention as a social process of collective action as it never refers to a single 'thing' that is to be implemented but rather a complex bundle of material and cognitive practices to be introduced into a social system. It follows that a process as complex as SDM needs substantial support and planning before and during widespread implementation into clinical areas to enable its success [19]. A theoretical framework of implementation characterises the elements of context and agency within a social system, that enable capacity to implement change [18]. May's [18] framework provides a template to understand health care contexts and the elements involved which act as barriers or enablers to implementation of new interventions. The key components of May's framework include potential, capacity, capability and contribution to implementation in practice.

A conceptual framework is an essential component for undertaking framework synthesis [20]. A framework guides decisions regarding analysis and assists in the interpretation of findings [21].

\subsection{Search Strategy}

The first author extensively reviewed the literature from August to December in 2015 and updated the search in November 2016. An anticipated complexity of the literature search was the multiple terms used independently and interchangeably for SDM. The heterogeneity of the concepts, definitions and terms used in relation to SDM has been described by other authors [22]. Makoul and Clayman [23], found in a review of 418 papers devoted to SDM that the terms "patient preference" and "options" were terms used in more than half. Policy documents frequently refer to "patient choices" [24] and "consumer participation" [25]. Cooper [26] supports incorporating the broadest conceptual definitions possible. 
Subsequently the search strategy was based on previously identified terms and concepts developed in a taxonomy and mapping of SDM [17]. Additional terms used to describe RAC internationally and traditionally were added (such as long term care and nursing homes). Because the focus was clinical practice, clinicians were defined by terms used internationally in the literature (care staff, nurses, allied health and medical staff). The search was adapted to each bibliographic database and Medical Subject Headings (MeSH) used where possible.

Search terms used for SDM and related concepts were;

"Shared decision making" OR "decision-making" OR "patient preference" OR "patient option" OR "patient choices" OR "consumer participation" OR "Consent" OR "guardianship" OR "advocacy" OR "proxy" OR "next of kin" OR "advance care plans" OR "patient centred care" OR "patient autonomy" OR "evidence based practice" OR "variations in care" OR "training" OR "education" OR "health literacy" OR "decision aids".

To capture the relevant literature in residential aged care settings, SDM search terms were combined with AND for: "residential aged care" OR "nursing home" OR "long term care" OR "care staff" OR "medical staff" OR "allied health" OR "nurses".

Bibliographic data bases searched included MEDLINE (Ovid), CINAHL, PsychINFO and Scopus.

\subsection{Inclusion/Exclusion Criteria}

Articles related to governance and occupational health and safety were excluded since the aim was to explore practice and processes relevant to SDM implementation in RAC. Studies conducted in settings other than RAC, such as community or transitional care, were excluded. Studies prior to 2005 were excluded to give a contemporary account of existing models and processes. Studies reported in languages other than English were also excluded. Qualitative and quantitative, or mixed methods research approaches were included, plus one case study due to its relevance to the topic under consideration. Systematic reviews were excluded but the reference lists were searched.

\subsection{Screening}

Quality appraisal of the methodology of the studies and risk of bias was not a central focus. Studies were critically appraised by the first author using the Critical Appraisal Skills Program (CASP) tool [27], to determine validity of the aims and methodological quality.

The search yielded 374 articles, Medline-153, PsychINFO-105, Scopus-47, CINAHL-44, Pubmed-27. Experts in the field of SDM were also contacted to provide other sources of potential studies, which provided three additional articles. The total was reduced to 300 when 76 duplicates were removed. Of the 300 remaining articles, 211 were excluded after reading the abstracts because they were not studies related to the search for models or processes of SDM in 
aged care, but focused on tool development or discussion or alternative settings. Eighty nine full text articles were screened and a further 62 excluded for being irrelevant to the research question. Of the 27 remaining articles, nine screened negatively to the two initial screening questions of the CASP and so were eliminated. The final 18 articles are described using the conceptual framework and synthesized using May's theory of implementation. A flow chart shows the selection process in Figure 1.

\section{Findings from the Literature Search}

Seventeen of the articles were published peer reviewed research articles and one a research report. The study designs, year of publication, country or origin, intervention, concept related to SDM and major findings are listed in Table 1. In addition, Table 1 shows the target population, whether the study was conducted with staff, residents or families or a combination. Ten of the studies included
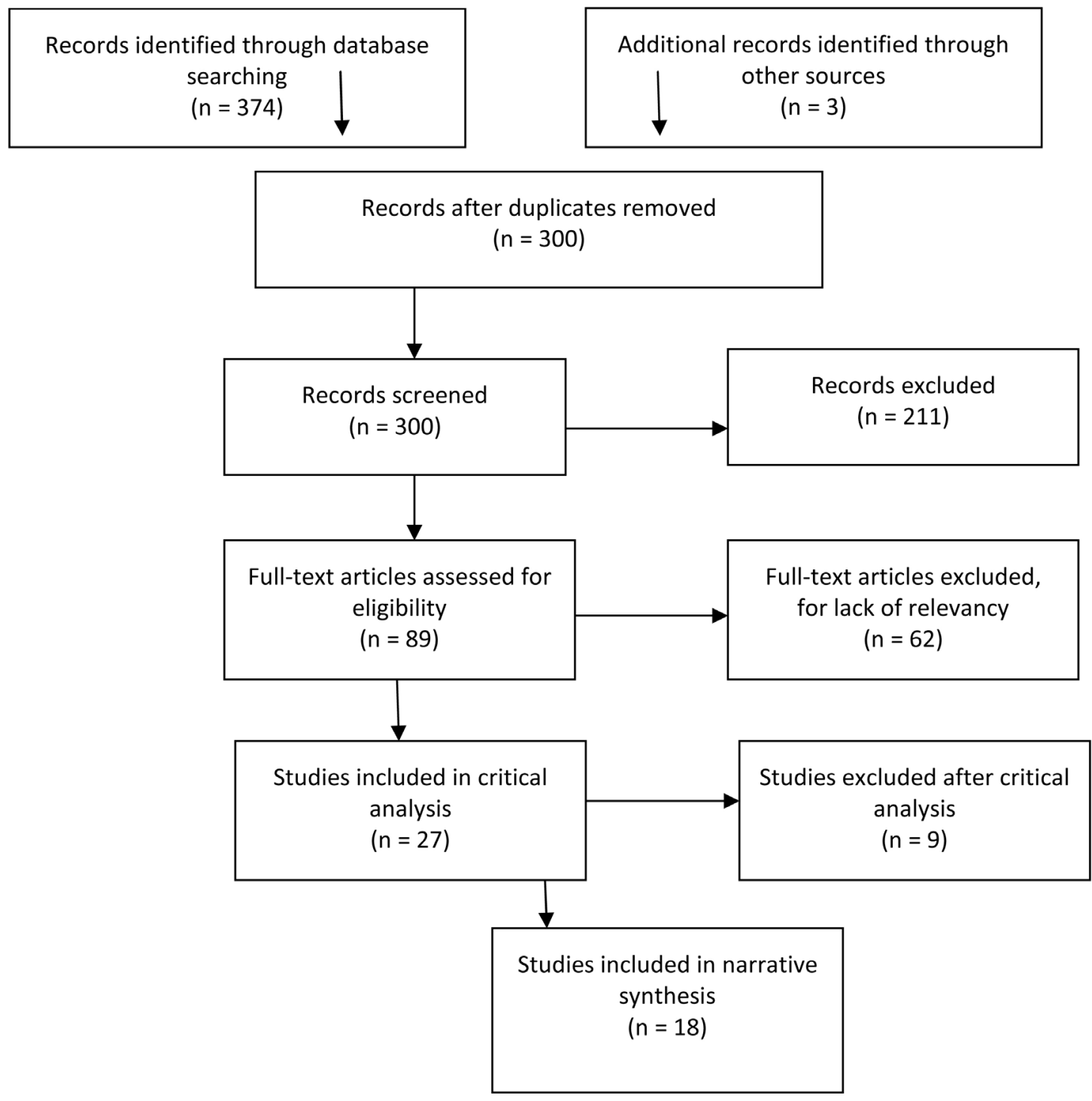

Figure 1. Process of article selection. 
Table 1. Summary of included studies related to SDM in residential aged care.

\begin{tabular}{|c|c|c|c|c|c|c|}
\hline Author-title & $\begin{array}{c}\text { Study } \\
\text { participants }\end{array}$ & Study aim & Country & Method & $\begin{array}{l}\text { Primary } \\
\text { concept } / s \\
\text { related to } \\
\text { SDM }\end{array}$ & $\begin{array}{l}\text { Finding-potential } \\
\text { barriers or } \\
\text { enablers to } \\
\text { SDM } \\
\text { implementation }\end{array}$ \\
\hline \multicolumn{7}{|c|}{ Qualitative } \\
\hline $\begin{array}{l}\text { Abrahamson, } \\
\text { K., Bernard, } \\
\text { B., Magnabosco, } \\
\text { L., Nazir, A., \& } \\
\text { Unroe, K. } \\
\text { The } \\
\text { experiences } \\
\text { of family } \\
\text { members in } \\
\text { the nursing } \\
\text { home to } \\
\text { hospital } \\
\text { transfer } \\
\text { decision. } \\
\text { (2016) [28] }\end{array}$ & Relatives & $\begin{array}{c}\text { The experiences of family } \\
\text { members in the nursing home } \\
\text { to hospital transfer decision } \\
\text { making process }\end{array}$ & USA & Interviews & $\begin{array}{l}\text { Readiness } \\
\text { Evidence } \\
\text { based } \\
\text { information }\end{array}$ & $\begin{array}{c}\text { Barrier } \\
\text { Information } \\
\text { on the risks of } \\
\text { hospitalisation } \\
\text { may assist family } \\
\text { members to } \\
\text { make decisions. } \\
\text { Family roles are } \\
\text { variable } \\
\text { depending } \\
\text { on readiness to } \\
\text { make decisions. }\end{array}$ \\
\hline $\begin{array}{l}\text { Arendts, G., } \\
\text { Popescu, A., } \\
\text { Howting, } \\
\text { D., Quine, } \\
\text { S., \& Howard, K. } \\
\text { “They never } \\
\text { talked to me } \\
\text { about...” } \\
\text { Perspectives } \\
\text { on aged care } \\
\text { resident transfer } \\
\text { to emergency } \\
\text { departments. } \\
\text { (2013) [29] }\end{array}$ & $\begin{array}{l}\text { Residents, } \\
\text { relatives and } \\
\text { staff }\end{array}$ & $\begin{array}{l}\text { To explore } \\
\text { perspectives } \\
\text { concerning } \\
\text { decisions to transfer } \\
\text { residents to } \\
\text { emergency } \\
\text { departments }\end{array}$ & Australia & Interviews & Readiness & $\begin{array}{c}\text { Barrier } \\
\text { SDM rarely occured, } \\
\text { staff were } \\
\text { paternalistic and denied } \\
\text { stakeholders choice. } \\
\text { Relatives } \\
\text { expressed both } \\
\text { unpreparedness to } \\
\text { make decisions and had } \\
\text { conflicting } \\
\text { opinions to staff. }\end{array}$ \\
\hline $\begin{array}{l}\text { Fetherstonhaugh, } \\
\text { D., Tarzia, L., } \\
\text { Bauer, M., Nay, } \\
\text { R. \& Beattie, E. } \\
\text { "The red dress } \\
\text { or the blue?" } \\
\text { How do staff } \\
\text { perceive that } \\
\text { they support } \\
\text { decision making } \\
\text { for people } \\
\text { with dementia } \\
\text { living in } \\
\text { residential aged } \\
\text { care facilities. } \\
\text { (2014) [30] }\end{array}$ & Staff & $\begin{array}{l}\text { Staff perceptions } \\
\text { of supported } \\
\text { decision } \\
\text { making for } \\
\text { residents with } \\
\text { dementia }\end{array}$ & Australia & $\begin{array}{l}\text { Interviews } \\
\text { and } \\
\text { focus } \\
\text { groups }\end{array}$ & PCC & $\begin{array}{c}\text { Enabler } \\
\text { Existing culture of PCC. } \\
\text { Staff awareness of } \\
\text { strategies to } \\
\text { support resident } \\
\text { decision making. } \\
\text { Informed } \\
\text { consent apparent in } \\
\text { staff ensuring } \\
\text { information was } \\
\text { understood. }\end{array}$ \\
\hline
\end{tabular}




\section{Continued}

Gjerberg, E.,

Lillemoen, L., Forde, R.,

\& Pedersen, $\mathrm{R}$.

End-of-life care

communications

and shared decision making in

Norwegian nursing

homes-experiences

and perspectives of

patients and

relatives.

(2015) [31]
Iden, K., Hjorleifsson, S., \& Ruths, S.

Treatment decisions on antidepressants in nursing homes: A qualitative study. (2011) [32]

Mann, E., Goff, S., Colon-Cartagena, W., Bellantonio, S., \&

Rothberg, M.

Do-not-hospitalize orders for individuals with advanced

dementia: Healthcare proxies perspectives.

(2013) [33]

Norheim, A., \&

Vinsnes, A.

Factors that influence patient involvement in nursing homes: staff experiences. (2012) [34] Families do-not-hospitalize

$\begin{array}{ccccc}\text { Residents } & \text { Perceptions of } & & \text { Interviews } & \\ \text { and } & \text { SDM in end of } & \text { Norway } & \text { and } & \text { Readiness } \\ \text { families } & \text { life care } & & \text { focus groups } & \end{array}$

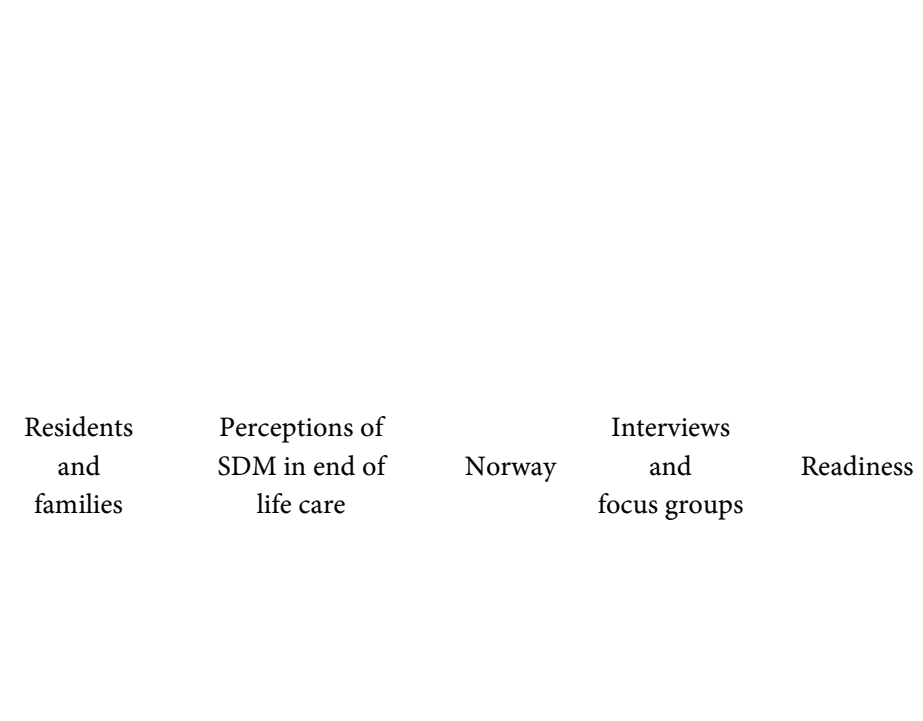

Explores health care proxies understanding of orders and why they may or may not initiate them

Explores decision making about treatment with antidepressants

Norway

$$
\begin{aligned}
& \text { Interviews } \\
& \text { and focus } \\
& \text { groups }
\end{aligned}
$$

information

USA Interviews information

Explores staff experience of

Staff factors influencing patient involvement
Evidence

based

Evidence based Readiness

Enabler

Explored readiness

for residents and

families in SDM

for end-of life care.

Found

that health care

professionals

should take

responsibility

for initiating

conversations and

involve families

with consent.

SDM should be

individualised

and iterative.

\section{Barrier}

Some residents and families expressed unpreparedness for SDM. Differences between residents in desire for SDM. Most relatives wanted to be involved in decisions but entrusted staff to make final decisions.

\section{Barrier}

Lack of EBP and resident/family involvement SDM in antidepressant prescription.

\section{Barrier}

No collaboration with families to improve capacity to make informed decisions that reflect individual values and wishes.

\section{Enabler}

Staff education in PCC. Staff stressed the importance of patient-centred

Education

$$
\begin{aligned}
& \text { attitudes for } \\
& \text { resident involvement in } \\
& \text { decision making. } \\
& \text { Barrier } \\
& \text { Time pressure was a key } \\
& \text { limiting factor to PCC. }
\end{aligned}
$$


O'Shea, F., Weathers, E., \& McCarthy, G. Family care experiences in nursing home facilities. (2014) [35]

Sims-Gould, J., McKay, H., Feldman, F., Scott, V., \& Ribonovitch, S. Autonomy, choice, patient-centred care and hip protectors: The experience of residents and staff in long term care. (2013) [36]

Tarzia, L.,

Fetherstonhaugh, D., Bauer, M., Beattie,

E \& Nay, R. "We have to work within the system!" Staff perceptions of organizational barriers to decision making for older adults with dementia in

Australian aged care facilities.

Explore relatives involvement in the care of older people admitted to RACF's

Ireland Interviews

PCC

Examine perceptions of staff and residents on

Residents and staff the decision to use hip protectors and factors which influence decisions
The perceptions of staff regarding organizational barriers that prevent facilitating decision making for residents with dementia
Semi-structured

Australia interviews and Focus groups.
PCC

Evidence

based information
Barrier

Families excluded from participating in decision making. Staff task oriented not PCC. Interventions that engage residents and their families in care required.

\section{Barrier}

Evidence based research took precedence over resident choice. Insistence on EBP even when explicitly declined by the resident.

\section{Barrier}

Staff perceived there was not enough time to facilitate decision making and that education and training is required for the skills as a facilitator. Policies and procedures needed to support practice in facilitated decision making.

\section{Quantitative}

Ampe, S., Sevenants, A., Smets, T.,

Declercq, A \&

Van Audenhove, C.

Advance care planning for nursing home residents with dementia: policy vs. practice. (2015) [38]
Evaluate advance care

planning policy for people with dementia, and family involvement in advance care planning in practice
Audit, self developed ACP questionnaire and ACP OPTION scale
Barrier

Staff failed to discuss the risks and benefits of treatment options with residents or their families. Strategies are required to translate ACP policy into practice.

Staff training is required and greater family involvement recommended.

\section{Enabler}

Resident and family readiness for SDM was assessed on admission. 


\section{Continued}

Eloranta, S., Arve, S.,

Isoaha, H., Aro, I.,

Kalam-Saliminen,

L. \& Routasalod, P.

Finnish nurses'

perceptions of care

of older patients. (2013)

[39]

Hanson, L., Carey, T., Caprio, A., Lee, T.,

Ersek, M.,

Garrett, J., Jackman, A., Gilliam, R., Wessell, K.,

\& Mitchell, $S$.

Improving

decision-making

for feeding options in

advanced

dementia: A

randomised,

controlled trial.

(2011) [40]

Helgesen, A., Athlin, E., $\&$ Larsson, $M$.

Relatives'

participation in

everyday care in

special care units

for persons with

dementia. (2015) [41]

Werner, $\mathrm{P}$.

Perceptions

regarding the use of

physical restraints with

elderly persons:

comparison of Israeli

health care nurses and

social workers. (2005)

[42]

\author{
Explores how \\ far nurses' \\ perceptions of care \\ Staff \\ take into account \\ preferences of older \\ patients \\ and their families
}

Testing quality of

Residents decision making about feeding

options using a decision aid

families

To determine relatives

participation in everyday care for

Families persons living in dementia specific facilities and

factors which influence it

To explore the perceptions of health care workers and social workers on the use of physical

restraints with elderly people
Questionnaire

(25 item

Finland purpose-designed from gerontological nursing literature)
RCT-Questionnaire (Decisional conflict scale administered at 1 and 3 months)
Questionnaire

$$
\text { (Study }
$$

Norway specific-derived from 2 previous studies by same researcher)

Evidence

based

information

Education

PCC

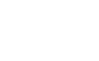


Bauer, M., Nay, R., Bathgate, T.,

Fetherstonhaugh, D., Winbolt, M., \& McAuliffe, L.

Constructive staff/family

relationships in residential aged care. (2009) [43]

Blackford, J.,

Strickland, E \&

Morris, B.

Advanced care planning in

residential aged care facilities.

(2007) [44]

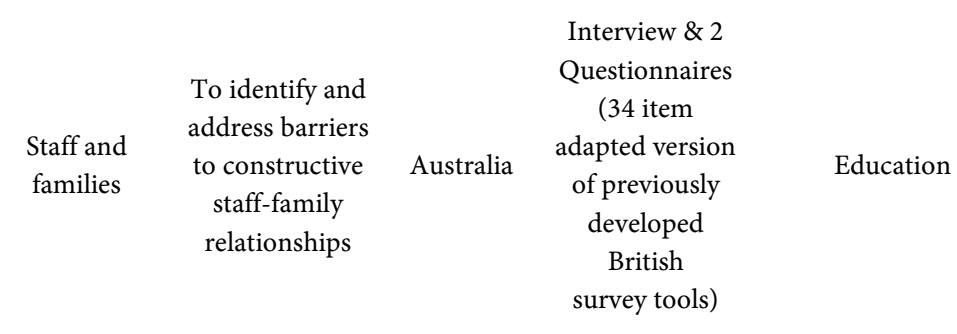

To describe

lessons learned

in

Staff

implementing

an advanced

care

planning

program
Enabler

Staff and family education in PCC,

information exchange

and communication

to facilitate

improvements in

staff-family

relationships.

Barrier

Differences in staff and

family perceptions about

information exchange and

communication (SDM).

\section{Enabler}

Collaborative decision making was facilitated by introduction of advanced care planning.

Barrier

Sustainability depended on governance structures, educational processes, resident documentation, quality audits and communication.

Varying success of sustainability over time. Resources and continued staff education are

required over a long time period.

\section{Case study}

Jeong, S., Higgins, I

\& McMillan, M.

Advance care

planning (ACP):

The nurse as

"broker" in

residential aged

care facilities.

(2007) [45]
To describe

how advanced

Residents,
families and
staff

care

planning is

implemented

and the role of a

clinical nurse

consultant

\section{Enabler}

Decision support and education for staff and families. Additional staff performed roles of mediation, assessment, intervention, coordination, communication and education in advanced care planning.

were published since 2013 and of the remaining eight only four are older than 2009.

Two of the studies retrieved explored SDM in RAC in the context of advance care planning. The other models focused on person-centred care, evidenced based care and models of advance care planning with perceptions of the con- 
cepts of decision making or shared decision making within each model, from the perspective of staff, residents and families. One of the studies aimed to measure the process of SDM as a primary outcome. The term "shared decision making" was only found in two of the studies.

The target populations of staff, residents and families was represented across the retrieved articles, providing perspectives of all groups about decision making processes, which helped to reduce bias of the findings collectively.

Eight of the studies are explicitly related to decision making in RAC, though only one described the process of SDM as described by Coulter and Collins [5]. All other studies are implicitly related and concerned with relevant concepts related to SDM, such as person centred care, evidence based practice and knowledge or education. Nine of the studies illustrate potential barriers to SDM implementation, three studies provide examples of potential enablers and the remaining six studies have elements of both barriers and enablers related to SDM implementation in RAC.

\section{Application of the Conceptual Framework of SDM}

\subsection{Person-Centred Care}

PCC is a dimension of quality care which is individualised to consider both the patient and their family as integral components of health care decision making and delivery of care [46]. As the essential component, or crux, of SDM [47] models of PCC are an important consideration in RAC. Six of the studies analysed concepts related to PCC [30] [34] [35] [41] [43]. These studies used qualitative [30] [34], quantitative research methods [41] and mixed methods [43] to provide the perspective of residents and families [35] [41] and staff [30] [34] or both groups [43] to illustrate the opinions of all stakeholders. Time pressure and a task oriented focus of care was a key limiting factor in providing PCC. Families were excluded from the decision making process when a PCC workplace culture was absent, though the families viewed their participation as crucial. Staff propose that an existing workplace culture of PCC is an enabler to supported decision making and family involvement [30] [34]. Importantly, the perceptions of staff and families differed about the level of communication and information exchange that was taking place, with staff perceiving higher levels of PCC than families [43].

Additional studies [29] [36] [39] included in the analysis illustrate that non PCC models of care result in a lack of SDM. A consistent finding was that paternalistic, task focused and evidence focused workplace cultures denied residents and families choice, from the perspectives of staff, residents and families [29] [36] [39].

If SDM is to be successfully implemented in RAC it requires a workplace culture of PCC, but evidence suggests that social norms in RAC may not align with PCC, and that residents, families and staff have differing opinions about the workability of PCC. 


\subsection{Evidenced-Based Practice}

Evidence is utilised in SDM to ensure that patients understand all the risks and benefits of associated care and treatment (informed consent) and to help them reach a decision based on their preferences [48] [49]. Like PCC, it is an essential component of the SDM process and utilisation of high quality research evidence demonstrates capacity for the implementation of SDM by workability.

Studies that utilised either qualitative [36] [42] or quantitative [40] designs as an intervention in RAC demonstrated contrasting results about potential SDM implementation. Perspectives of residents and families [40], residents and staff [36] or staff alone [37] [42] are reported in each of these studies. A top down approach to utilising evidence [36] [42], where staff held the knowledge of best practice, denied residents choice and autonomy, while a bottom up approach [40], where families were provided with evidence of treatment risks and benefits increased family members knowledge and facilitated SDM with staff. Staff as reported in Sims-Gould et al. study [36] perceived that evidence based practice should take precedence over resident choice, while staff in Werner's study [42] expressed moral and ethical issues about utilising evidence that is known to abrogate resident autonomy. In another study by Hanson et al. [40], there is no knowledge of staff opinions of a bottom up approach to utilising evidence. Without staff perspectives of a bottom up approach, understanding of potential implementation is limited.

Four articles focused on advance care planning (ACP) or end-of-life care, two quantitatively measured [38] [44] staff perspectives, one case study [45] described perspectives of all stakeholders and three qualitative methodological approaches [31] [33] focused on residents and families. None of the articles describe utilising evidence to help residents or their families decide on treatment options. Two studies found a lack of provision of information to residents and their families, and reported that staff rarely discussed the risks and benefits of treatment options [28] [38]. Some families indicated that there was a lack of information provided to them to assist in decision making [33]. This suggests that poor knowledge may result in some families deferring decision making to staff, though other families expressed a desire to be part of the decision making process. Staff perceived it was unfair to expect families to make decisions without knowledge of the risks and benefits of the treatment option, and so believed that their expert knowledge justified them as decision makers [29].

\subsection{Readiness of Residents, Staff and Organisations}

There is evidence that some patients prefer not to be involved and to leave decisions about treatment to clinicians [19] [50]. The reasons for this are multi-factorial, but an important consideration. Additionally, clinician and organisation readiness for the process of SDM is vital to implementation. Readiness to participate in SDM was highlighted in five of the studies regarding ACP and endof-life care [31] [33] [38] [44] [45], the study methodology and stakeholder perspectives having already been described but which includes a mixture of qua- 
litative and quantitative methodologies plus a case study involving all stakeholder perspectives.

There are differences in the level of involvement residents and families wish to have in decision making in ACP and end-of-life care. Resident and family readiness to participate was shown to be a significant factor in the process of collaborative decision making. Perspectives of residents and families willingness to be involved in decision making varied within and across studies. Residents and families often give staff an imprimatur to make decisions on the resident's behalf, rather than being involved [29] [31]. Importantly, some families were stressed and uncertain if expected to make a decision, but postulated that this may be a result of poor knowledge of the consequences of their decision [29]. Alternatively, some family members expressed dissatisfaction with being excluded from the decision making process [29] [31]. The study by Ampe et al. [38] demonstrated that readiness of families to be involved in SDM was assessed by inquiring about their preferred approach to receiving information to assist in SDM.

Staff and organisation readiness is paramount to effective SDM [29] [32] [34] [35] [36] [39] [41]. A lack of PCC was the limiting factor in staff and organisation readiness for SDM. Staff unpreparedness for SDM was highlighted in two of the studies [36] [39], while organisational unpreparedness was perceived as a barrier in two [39]. Frequently, the unpreparedness or lack of readiness could be attributed to both staff and organisational factors [29] [32] [35] [41]. Organisational readiness was also identified as having policies to support SDM in practice by two studies [37] [38].

There can be multiple factors contributing to staff and organisation readiness [32] which requires a huge organisation cultural shift [43]. Education was identified as paramount in staff, family and organisational readiness for implementing change.

\subsection{Education}

Much of the broader literature on SDM, focuses on education for clinicians on how to execute the process of SDM [51] [52], what SDM is [53] [54] and why it is important [6]. Education in SDM was not a focus of any of the articles retrieved, however, many of them utilised education to execute and embed models of care [30] [43] or enact organisational change to adopt new processes [44] [45] and are thus particularly relevant to SDM in RAC if it is to be implemented. Education in SDM was recommended in two studies, [28] [38] particularly about the importance of family involvement. The articles analysed which utilised an educational intervention were predominantly quantitative approaches [40] [43] [44]. Hanson et al. [40] differed by providing education to families not staff, while Bauer et al. [43] provided education to staff and families concurrently. All of the studies concerned with education excluded the perceptions of residents and focused on staff and families.

Staff and family education in collaborating together is illustrated as the corner 
stone for successful implementation of new interventions [43]. It is also important to seek staff opinion on factors which mitigate against collaborating with families [34] [43]. Discussion with family members on treatment options is crucial to SDM [28] [38] [40]. Education can be resource intensive, particularly if it focuses on embedding long term, sustained adoption of change [44] [45].

\subsection{Documentation, Communication and Enactment}

The third component of Coulter and Collins SDM process [5] is documentation of the decision reached, communication between stakeholders and enactment of the treatment choice. Without this final component, the previous components have no validity in the process of SDM. Documenting and communicating residents preferences so that they can be enacted are the operational phase of SDM.

There were six articles concerned with the components of documentation, communication and execution of care in RAC settings, three articles used a quantitative research design [29] [33] [44], a case study [45], and three used qualitative methodology [29]. Arendts et al. [29] provides perspectives of staff, residents and families, while the other articles focus on staff [34] [44] or families [33] alone, or is purely descriptive [45].

A support worker (facilitator or broker) was perceived as the key to implementation of Advance Care Planning (ACP) [44] [45]. The support workers role is to educate staff and families about process and act as a mediator. The support worker initiates discussion with all stakeholders and facilitates the implementation of goals and plans. Involvement of residents and relatives in understanding the process of an intervention is central to successful implementation. The importance of information exchange and communication between stakeholders is emphasized [34]. Barriers to execution of wishes include a lack of documented resident preferences [33], or inadequate planning and communication [29]. Systematic operationalization of an intervention requires regular and ongoing education of all stakeholders [44] as well as auditing of existing processes, policies and strategic planning about organisational changes that may be required for success [28] [37]. High staff turn-over and changes to management of RAC is a threat to sustainability of interventions [44]. Blackford et al. [44] describe a system-wide approach to documentation, communication and dissemination of a residents wishes as paramount to success.

\section{Narrative Synthesis Procedure Utilising an Implementation Framework}

The perceptions of the population groups (stakeholders) regarding the components of SDM (person-centredness, evidence, education and documentation and communication of decisions) are important in illustrating the extent to which each component can serve as a potential barrier or enabler to implementation in practice in a RAC setting. The final part of this synthesis aimed to determine how the components of SDM relate to implementation in practice.

May's theoretical framework of implementation [18] was utilised to under- 
stand how the essential components of SDM potentially facilitated or abrogated the process of SDM. An important step in the analysis was to compare and contrast the perceptions of the different populations (staff, residents and families) both within each study and across studies. In light of the predominantly qualitative methodologies of the extant literature, the analysis used a framework synthesis approach to bring together the current evidence [55] and reach conclusions.

Although there are a plethora of implementation frameworks [56] [57], May's framework specifically relates to the complex hierarchical structures of health care settings and potential complex interventions that may be introduced. May's framework recognises that implementation is not simplistic.

How the theoretical framework of implementation [18] was applied to the components of SDM is shown in Figure 2. The subject of the "social system" [18] for implementation in this analysis is residential aged care. The "element of context" [18] is the capacity and potential of RAC to implement SDM.

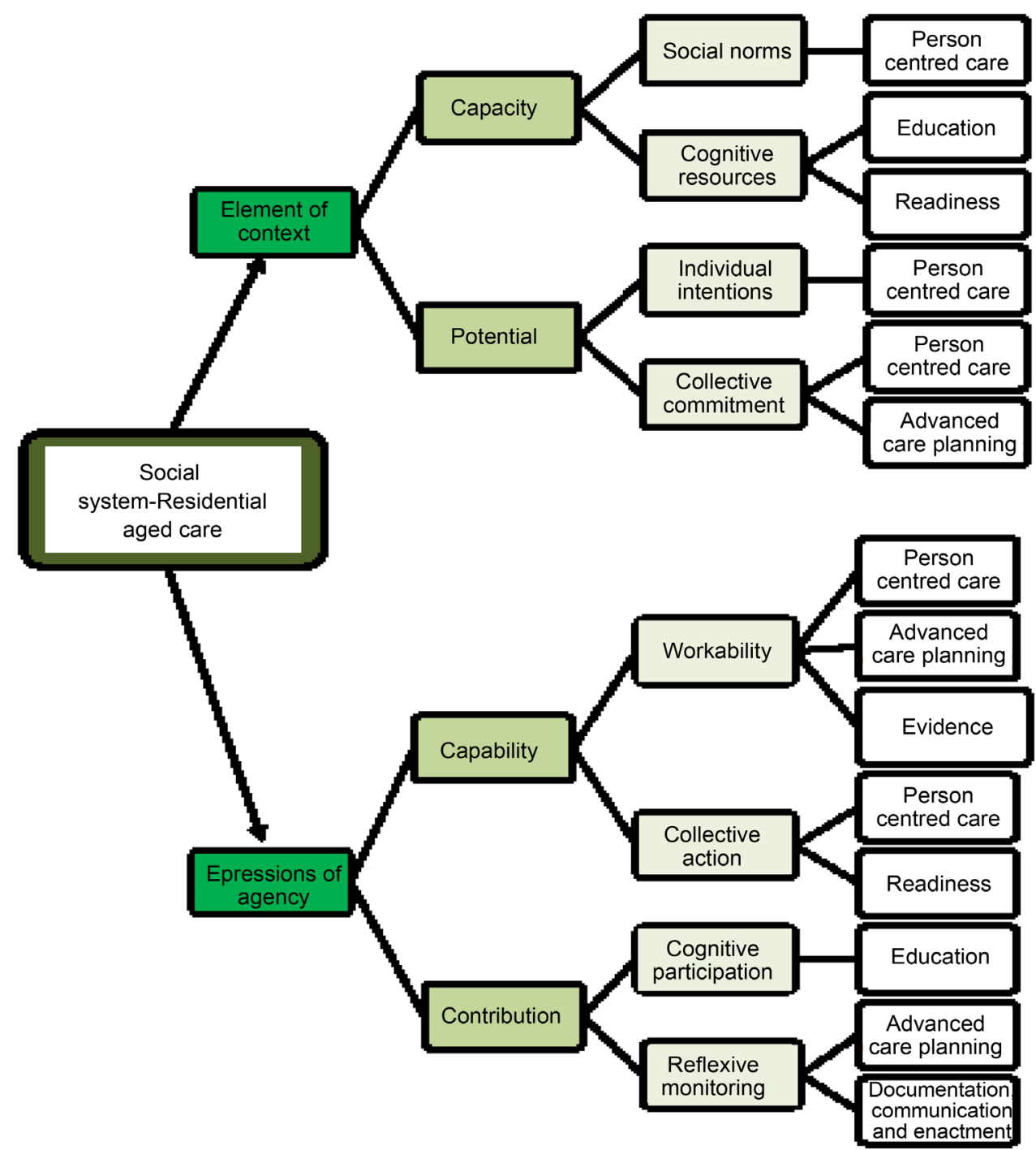

Figure 2. Application of theoretical framework of implementation [18] to the components of SDM. 
Potential for implementation relies on organisational readiness, shown through individual intention and shared commitment. Implementation theory describes individual intentions and shared commitment as agents (clinicians, residents and families) motivation to translate beliefs and attitudes into behaviours that align with the social system. Capacity for implementation is dependent on material (access to resources needed for operationalization) and cognitive resources (knowledge, information and evidence) as well as social norms (institutionally sanctioned rules within the social system).

"Expressions of agency" [18] in this analysis are identified by capability and contribution of stakeholders to implement SDM. Capability for implementation relates to workability-social practices the agents perform in enacting or operationalizing an intervention. Contribution in the implementation framework relates to cognitive participation and collective action (how agents enrol themselves or mobilise skills to enact interventions) and reflexive monitoring (appraisal of the intervention).

\section{Discussion}

The initial literature search aimed to review current practices of SDM concepts in RAC and the synthesis to describe potential implementation of SDM in RAC using implementation theory framework. It is evident that SDM, as described by Coulter and Collins [5] has not been implemented fully in aged care settings. There is also evidence that the full concept of SDM is rarely implemented in any health care settings [52], even when clinicians have been trained in the process. This suggests that clinician training on cognitive resources is only one of the many factors required and that implementation of SDM in practice is complex.

\subsection{Capacity}

Capacity, in terms of RAC, is bound up in the social norms that govern behaviour within it. Paternalistic attitudes are a common social norm in RAC [29] [36] [39] [58] and the antithesis of SDM-there is an imbalance of power between clinicians and patients created by law and specialist knowledge [59]. Paternalism is frequently driven by clinician's belief that they know what is best for patients. There is a tension between strong commitment by staff to keeping residents safe and violating their right to choice and autonomy [36] [39]. For SDM to be effective clinicians must relinquish their role as the single, paternalistic authority and train to become more effective coaches or partners [2]. The greatest challenge is turning the rhetoric into reality, changing workplace culture requires a huge shift in the common social norms of many RAC facilities [43]. Respect for a person's right to make choices and participate in decision making is generally viewed as central to quality of life and well-being [30], however existing social norms in residential aged care potentially prevents SDM implementation [37].

A culture of person centred care is fundamental to SDM, and a recurring theme in the articles reviewed [30] [31] [34] [35] [41] [43]. PCC is a required social norm for implementation of SDM and SDM is viewed as a strategy that in- 
corporates PCC principles into standards of care [60]. An audit tool has been developed to measure PCC in RAC settings, which aims to minimise staff bias of their perception of providing PCC [61]. Auditing PCC, as an essential component of SDM, is paramount to determine capacity for implementation. Implementation involves interaction with other agents, processes and contexts [18]. A workplace culture of PCC indicates capacity for SDM implementation, one factor of readiness. As well as organisational readiness, readiness of residents and their families is an essential component of capacity to implement SDM.

Material resources within a social system including their distribution and allocation are also a dimension of capacity. Similarly, shared commitment requires that participants are induced to participate, and Implementation Theory recognises that coercion, rather than motivation may be a strategy used to constrain others. SDM utilises evidence to inform the patient of the risks and benefits of various treatment options, to support their decisions [51] [62], not to coerce patients into practices or treatments that conflict with their preferences and values. Patient preference is a warranted variation to best practice initiatives [63].

Evidence can be utilised through the provision of patient decision aids. Although decision aids do not guarantee that decision making will be shared [64] [65] they offer a structured way to provide detailed information about treatment choices [1]. Decision aids are valuable for patients with low literacy levels [65] and so provide real hope for facilitating SDM with various population groups. Although decision aids have demonstrated effectiveness about increasing patient knowledge and risk perception, SDM is not dependent on them [6]. While increasingly available, a decision aid, or quality evidence may not necessarily exist for the condition under consideration, or the evidence may be rapidly changing. Clinicians must be able to access up-to-date evidence, evaluate quality and ensure that they are appropriate for the patient and their condition [66], skills the clinician may not possess. Utilising decision aids is not straight forward [6]. The implementation theory framework suggests that agent's capacity relies upon cognitive and material resources [18]. Knowledge of how to access, interpret and apply evidence will be crucial to successful implementation of SDM.

The provision of resources to both educate staff and families [34] [42] [43] [44] [45], and promote sustainability increases capacity to implement SDM in RAC. The provision of education in SDM is widely supported [28] [37] [67] [68]. Paradoxically, the resources necessary to implement SDM, such as increased time, support workers and overall governance, may also be a barrier. RAC settings are typically busy, time poor environments [30]. Time constraints are a limiting factor for practicing PCC [34], and also found to be true for SDM [37] [38]. Additional resources and dedicated funding are required to embed SDM practice within RAC facilities.

\subsection{Potential}

Lack of resident and family readiness for SDM is a barrier to potential implementation [29] [31]. Resident and family readiness relates to individual inten- 
tion. Clinicians must first assess the patients preferred level of involvement in decision making [67] [69]. Previous authors of SDM studies [67] emphasize the importance of flexibility and warn that strict adherence to the principles of SDM risks another form of paternalism. Some patients prefer not to be involved and to leave decisions about treatment to clinicians [31]. It is recommended [68] that for SDM to become embedded requires a bottom up approach, where patients have an expectation that decision making will be negotiated together. The current regulatory pressures in many countries [54] to adopt SDM ignores that flexibility must be maintained, and that patient autonomy begins with the preferred level of involvement. Non participation in the decision making process, is in itself SDM, provided that risks and benefits of treatment options are clearly articulated and understood. Individual intention and collective commitment to SDM demonstrate potential to implement it. The object of an implementation process may be a modified way of thinking, where the agent intentionally makes things happen by action.

\subsection{Contribution and Capability}

Like capacity, much of contribution and capability relate to PCC. SDM includes collaboration (collective action) with families as appropriate and emotional and physical support [70]. Contribution includes cognitive participation and reflexive monitoring. Joint action, such as sharing of information, unites two or more individuals towards a shared end. Documentation and dissemination of resident choices are essential to operationalize SDM [44]. Capability is concerned with the dimension of workability-operationalizing the intervention. Communication between all stakeholders is necessary for dissemination of information but there is evidence that clinicians and residents/families do not communicate well [59]. There is also evidence that enhanced communication can be achieved through a process of education of staff and families on how to collaborate more effectively [43]. To successfully implement and embed SDM will require RAC facilities to undertake reflexive monitoring or appraisal of the effects of SDM to ensure that property is shared, not a single entity. Reflexive monitoring frames how participants collect and utilise information about the effects of the intervention.

\section{Conclusion}

The most important finding of the synthesis is that the implementation of SDM in RAC, hinges on a person centred culture of care. Paternalistic practices of staff hinder person-centred care and capacity to implement SDM in RAC. Operationalization of SDM practice may be dependent on additional resources in the facilities. As well as a person-centred culture of care, cognitive and material resources such as education of staff and residents/families are important enablers to implementation of SDM. Readiness or preparedness of residents and families to be involved in SDM should be ascertained as part of the process. Importantly this synthesis highlights the caution that must be exercised in introducing research based evidence into practice to ensure that it is utilised to assist in deci- 
sion making but balanced with residents' preferences and values. Additionally, evidence needs to be provided in simple, easily understood formats (such as decision aids) to facilitate knowledge and understanding of the information provided and increase workability.

\section{Recommendations}

Implementation of any health care intervention, including SDM, relies on many complex factors but these are predominantly related to multi-dimensional aspects of capacity. If there is to be effective implementation of SDM, auditing capacity within the system of RAC is required. The synthesis indicates that capacity relies on workplace culture and organisational support for resources such as support workers and education for staff and residents to increase readiness.

To date, little research has been undertaken in RAC to determine staff knowledge, or previous training in SDM. Additionally, little is known about the uptake of SDM in RAC. The absence of studies may not reflect current practice. Aged care quality standards emphasise resident choice, so processes which support this must exist to meet minimum requirements. How regulatory agencies assess this is unclear and not the subject of peer reviewed publications.

As a starting point, rigorous evaluation is required to measure readiness of organisations and residents and families for implementation of SDM processes. This will provide a baseline for future SDM intervention studies.

\section{Ethical Approval}

Not applicable, no human research was involved.

\section{Competing Interests}

The authors declare they have no competing interests.

\section{Acknowledgements}

The John Richards Initiative, LaTrobe University contributes salary for IB and funding for $\mathrm{KE}$ as a $\mathrm{PhD}$ candidate. This work was supported by the Australian Government Department of Health through the University Department of Rural Health program for the salaries of $\mathrm{KE}$ and $\mathrm{HH}$.

\section{References}

[1] Charles, C., Gafni, A. and Whelan, T. (1999) Decision-Making in the Physician-Patient Encounter: Revisiting the Shared Treatment Decision-Making Model. Social Science \& Medicine, 49, 651-661.

[2] Barry, M.J., Edgman-levitan, S. and Billingham, V. (2012) Shared Decision Making-The Pinnacle of Patient-Centered Care. The New England Journal of Medicine, 366, 780-781. https://doi.org/10.1056/NEJMp1109283

[3] Australian Commission on Safety and Quality in Health Care (2015) Shared Decision Making. http://www.safetyandquality.gov.au/ http://www.safetyandquality.gov.au/our-work/shared-decision-making/ 
[4] King, J.S. and Moulton, B.W. (2006) Rethinking Informed Consent: The Case for Shared Medical Decision-Making. American Journal of Law \& Medicine, 32, 429501. https://doi.org/10.1177/009885880603200401

[5] Coulter, A. and Collins, A. (2011) Making Shared Decision Making a Reality. No Decision about Me, without Me. Kings Fund, 1-56.

http://www.kingsfund.org.uk/publications/nhs_decisionmaking.html

[6] Hoffmann, T.C., Légaré, F., Simmons, M.B., McNamara, K., McCaffery, K., Trevena, L.J., et al. (2014) Shared Decision Making: What Do Clinicians Need to Know and Why Should They Bother? The Medical Journal of Australia, 201, 35-39.

http://www.ncbi.nlm.nih.gov/pubmed/24999896 https://doi.org/10.5694/mja14.00002

[7] Greenhalgh, T., Howick, J. and Maskrey, N. (2014) Evidence Based Medicine: A Movement in Crisis? BMJ, 348, g3725-g3725.

http://www.bmj.com/cgi/doi/10.1136/bmj.g3725 https://doi.org/10.1136/bmj.g3725

[8] Légaré, F., Stacey, D., Brière, N., Fraser, K., Desroches, S., Dumont, S., et al. (2013) Healthcare Providers' Intentions to Engage in an Inter-Professional Approach to Shared Decision-Making in Home Care Programs: A Mixed Methods Study. Journal of Interprofessional Care, 27, 214-222.

http://www.pubmedcentral.nih.gov/articlerender.fcgi?artid=3665231\&tool=pmcent rez\&rendertype $=$ abstract https://doi.org/10.3109/13561820.2013.763777

[9] N.A. (2012) Living Longer, Living Better-Aged Care Reform Package. Department of Health and Ageing.

http://www.health.gov.au/internet/publications/publishing.nsf/Content/ageing-aged -care-reform-measures-toc ageing-aged-care-reform-measures-chapter2.htm $\backslash \mathrm{n}$ http://www.health.gov.au/internet/publications/publishing.nsf/Content/ageing-livin g-longer-living-bet

[10] Kaiser Family Foundation (2011) Summary of New Health Reform Law. 1-13. http://www.kff.org/healthreform/upload/8061.pdf

[11] Badham, J. and Sinfield, M. (2003) Essence of Care Patient-Focused Benchmarks for Clinical Governance. Communication, 1-175.

[12] World Health Organisation (2006) Quality of Care : A Process for Making Strategic Choices in Health Systems. Geneva, 8, 38. http://www.who.int/iris/handle/10665/43470

[13] 111th United States Congress (2010) Patient Protection and Affordable Care Act. Public Law, 111-148.

[14] NHS England. Shared Decision Making.

[15] Ritchie, J. and Spencer, L. (1994) Qualitative Data Analysis for Applied Policy Research. In: Bryman, A. and Burgess, R., Eds., Anal. Qual. Data, Routledge, London, 173-194. https://doi.org/10.4324/9780203413081_chapter_9

[16] Booth, A. and Carroll, C. (2015) How to Build Up the Actionable Knowledge Base: The Role of "Best Fit" Framework Synthesis for Studies of Improvement in Healthcare. BMJ Quality \& Safety, 4, 700-708. https://doi.org/10.1136/bmjqs-2014-003642

[17] Ervin, K., Blackberry, I. and Haines, H. (2017) Developing a Taxonomy and Mapping Concepts of Shared Decision Making to Improve Clinicians Understanding. Nursing \& Care Open Access Journal, 3, Article No. 00063. http://medcraveonline.com/NCOAJ/NCOAJ-03-00063.pdf

[18] May, C. (2013) Towards a General Theory of Implementation. Implementation 
Science, 8, 18.

http://www.scopus.com/inward/record.url?eid=2-s2.0-84875362066\&partnerID=tZ Otx3y1 https://doi.org/10.1186/1748-5908-8-18

[19] Lally, J. and Tullo, E. (2012) Engaging Older People in Decisions about Their Healthcare: The Case for Shared Decision Making. Reviews in Clinical Gerontology, 22, 99-107. https://doi.org/10.1017/S0959259811000281

[20] Carroll, C., Booth, A., Leaviss, J. and Rick, J. (2013) “Best Fit” Framework Synthesis: Refining the Method. BMC Medical Research Methodology, 13, 37. https://doi.org/10.1186/1471-2288-13-37

[21] Snilstveit, B., Oliver, S. and Vojtkova, M. (2012) Narrative Approaches to Systematic Review and Synthesis of Evidence for International Development Policy and Practice. Journal of Development Effectiveness, 4, 409-429.

[22] Clark, N., Nelson, B., Valerio, M., Gong, Z., Taylor-Fishwick, J. and Fletcher, M. (2009) Consideration of Shared Decision Making in Nursing: A Review of Clinicians' Perceptions and Interventions. The Open Nursing Journal, 3, 65-75. https://doi.org/10.2174/1874434600903010065

[23] Makoul, G. and Clayman, M. (2006) An Integrative Model of Shared Decision Making in Medical Encounters. Patient Education and Counseling, 60, 301-312.

[24] Austin Health (2006) Respecting Patient Choices. https://www.caresearch.com.au/caresearch/tabid/92/Default.aspx

[25] Australian Government D of H (2011) Model and Definition of Consumer Participation. http://health.gov.au/internet/publications/publishing.nsf/Content/illicit-pubs-needl e-tsu2-toc illicit-pubs-needle-tsu2-2

[26] Cooper, H.M. (1989) Integrating Research: A Guide for Literature Reviews. 2nd Edition, Sage, Newbury.

[27] Clisby, N. and Charnock, D. (2000) DISCERN/CASP Workshop Final Project Report. Critical Appraisal Skills Programme. Institute of Health Sciences, Oxford.

[28] Abrahamson, K., Bernard, B., Magnabosco, L., Nazir, A. and Unroe, K.T. (2016) The Experiences of Family Members in the Nursing Home to Hospital Transfer Decision. BMC Geriatrics, 16, 184.

http://bmcgeriatr.biomedcentral.com/articles/10.1186/s12877-016-0359-2 https://doi.org/10.1186/s12877-016-0359-2

[29] Arendts, G., Popescu, A., Howting, D., Quine, S. and Howard, K. (2015) “They Never Talked to Me about...": Perspectives on Aged Care Resident Transfer to Emergency Departments. Australasian Journal on Ageing, 34, 95-102.

http://search.ebscohost.com/login.aspx?direct=true \&db=cmedm\&AN=24372732\&si te=ehost-live

https://doi.org/10.1111/ajag.12125

[30] Fetherstonhaugh, D., Tarzia, L., Bauer, M., Nay, R. and Beattie, E. (2014) “The Red Dress or the Blue?": How Do Staff Perceive That They Support Decision Making for People with Dementia Living in Residential Aged Care Facilities? Journal of Applied Gerontology, 1-18. http://www.ncbi.nlm.nih.gov/pubmed/24762711

[31] Gjerberg, E., Lillemoen, L., Forde, R. and Pedersen, R. (2015) End-of-Life Care Communications and Shared Decision Making in Norwegian Nursing HomesExperiences and Perspectives of Patients and Relatives. BMC Geriatrics, 15, 103.

[32] Iden, K.R., Hjørleifsson, S. and Ruths, S. (2011) Treatment Decisions on Antidepressants in Nursing Homes: A Qualitative Study. Scandinavian Journal of Primary 
Health Care, 29, 252-256.

http://www.pubmedcentral.nih.gov/articlerender.fcgi?artid=3308458\&tool=pmcent rez\&rendertype $=$ abstract https://doi.org/10.3109/02813432.2011.628240

[33] Mann, E., Goff, S.L., Colon-Cartagena, W., Bellantonio, S. and Rothberg, M.B. (2013) Do-Not-Hospitalize Orders for Individuals with Advanced Dementia: Healthcare Proxies' Perspectives. Journal of the American Geriatrics Society, 61, 1568-1573. http://www.ncbi.nlm.nih.gov/pubmed/23888937 https://doi.org/10.1111/jgs.12406

[34] Norheim, A. and Vinsnes Guttormsen, A. (2012) Factors That Influence Patient Involvement in Nursing Homes: Staff Experiences. Nordic Journal of Nursing Research, 32, 42-46.

http://journals.sagepub.com/doi/abs/10.1177/010740831203200309

[35] O’Shea, F., Weathers, E. and McCarthy, G. (2014) Family Care Experiences in Nursing Home Facilities. Nursing Older People, 26, 404-416.

[36] Sims-Gould, J., McKay, H.A., Feldman, F., Scott, V. and Robinovitch, S.N. (2014) Autonomy, Choice, Patient-Centered Care, and Hip Protectors: The Experience of Residents and Staff in Long-Term Care. Journal of Applied Gerontology, 33, 690 709. https://doi.org/10.1177/0733464813488658

[37] Tarzia, L., Fetherstonhaugh, D., Bauer, M. and Nay, R. (2015) "We Have to Work within the System!” Staff Perceptions of Organizational Barriers to Decision Making for Older Adults with Dementia in Australian Aged Care Facilities. Research in Gerontological Nursing, 8, 286-292. https://doi.org/10.3928/19404921-20150413-01

[38] Ampe, S., Sevenants, A., Smets, T., Declercq, A. and Van Audenhove, C. (2015) Advance Care Planning for Nursing Home Residents with Dementia: Policy vs. Practice. Journal of Advanced Nursing, 72, 569-581.

[39] Eloranta, S., Arve, S., Isoaho, H., Aro, I., Kalam-Salminen, L. and Routasalod, P. (2014) Finnish Nurses' Perceptions of Care of Older Patients. International Journal of Nursing Practice, 20, 204-211. https://doi.org/10.1111/ijn.12137

[40] Hanson, L.C., Carey, T.S., Caprio, A.J., Lee, T.J., Ersek, M., Garrett, J., et al. (2011) Improving Decision-Making for Feeding Options in Advanced Dementia: A Randomized, Controlled Trial. Journal of the American Geriatrics Society, 59, 20092016. https://doi.org/10.1111/j.1532-5415.2011.03629.x

[41] Helgesen, A., Athlin, E. and Larsson, M. (2015) Relatives' Participation in Everyday Care in Special Care Units for Persons with Dementia. Nursing Ethics, 22, 404-416. https://doi.org/10.1177/0969733014538886

[42] Werner, P. (2002) Perceptions Regarding the Use of Physical Restraints with Elderly Persons: Comparison of Israeli Health Care Nurses and Social Workers. Journal of Interprofessional Care, 16, 59-68.

http://search.ebscohost.com/login.aspx?direct=true $\& \mathrm{db}=\mathrm{psyh} \& \mathrm{AN}=2002-10812-00$ $3 \&$ site $=$ ehost-live https://doi.org/10.1080/13561820220104177

[43] Bauer, M., Nay, R., Bathgate, T., Fetherstonhaugh, D., Winbolt, M. and McAuliffe, L. (2009) Constructive Staff/Family Relationships in Residential Aged Care. ACEBAC. La Trobe University.

[44] Blackford, J., Strickland, E. and Morris, B. (2007) Advance Care Planning in Residential Aged Care Facilities. Contemporary Nurse: A Journal for the Australian Nursing Profession, 27, 141-151.

http://search.ebscohost.com/login.aspx?direct=true \&db=cin20\&AN=2010036399\&a mp;lang=ja\&site=ehost-live 
[45] Jeong, S., Higgins, I. and McMillan, M. (2007) Advance Care Planning (ACP): The Nurse as "Broker" in Residential Aged Care Facilities. Contemporary Nurse, 26, 184-195. https://doi.org/10.5172/conu.2007.26.2.184

[46] Hughes, R. (2011) Overview and Summary: Patient-Centred Care: Challenges and Rewards. The Online Journal of Issues in Nursing, Vol. 16.

[47] Legare, F., Elwyn, G., Fishbein, M., Fremont, P., Frosch, D., Gagnon, M., et al. (2008) Translating Shared Decision-Making into Health Care Clinical Practices: Proof of Concepts. BioMed Central, 3.

[48] Coulter, A., Parsons, S. and Askham, J. (2008) Where Are the Patients in Decision-Making about Their Own Care? WHO Regional Office for Europe and European Observatory on Health Systems and Policies, 14.

http://www.who.int/management/general/decisionmaking/WhereArePatientsinDec isionMaking.pdf

[49] Elwyn, G., Tilburt, J. and Montori, V.M. (2012) The Ethical Imperative for Shared Decision-Making. European Journal for Person Centered Healthcare, 1, 129-131. https://doi.org/10.5750/ejpch.v1i1.645

[50] Miller, L.M., Whitlatch, C.J. and Lyons, K.S. (2014) Shared Decision-Making in Dementia: A Review of Patient and Family Carer Involvement. Dementia. http://www.ncbi.nlm.nih.gov/pubmed/25370075

[51] Elwyn, G., Frosch, D., Thomson, R., Joseph-Williams, N., Lloyd, A., Kinnersley, P., et al. (2012) Shared Decision Making: A Model for Clinical Practice. Journal of General Internal Medicine, 27, 1361-1367. https://doi.org/10.1007/s11606-012-2077-6

[52] Elwyn, G., Hutchings, H., Edwards, A., Rapport, F., Wensing, M., Cheung, W.Y., et al. (2005) The Option Scale: Measuring the Extent That Clinicians Involve Patients in Decision-Making Tasks. Health Expectations, 8, 34-42. https://doi.org/10.1111/j.1369-7625.2004.00311.x

[53] Friesen-Storms, J.H., Bours, G.J., van der Weijden, T. and Beurskens, A.J. (2015) Shared Decision Making in Chronic Care in the Context of Evidence Based Practice in Nursing. International Journal of Nursing Studies, 52, 393-402.

[54] Godolphin, W. (2009) Shared Decision-Making. Healthcare Quarterly, 12, 186-190. https://doi.org/10.12927/hcq.2009.20947

[55] Popay, J., Roberts, H., Sowden, A., Arai, L., Rogers, M. and Britten, N. (2003) Developing Guidance on the Conduct of Narrative Synthesis in Systematic Reviews. ESRC Methods Program, 1.

[56] Graham, I., Logan, J., Harrison, M., Straus, S., Tetroe, J. and Caswell, W. (2006) Lost in Knowledge Translation: Time for a Map? Journal of Continuing Education in the Health Professions, 26, 13-24. https://doi.org/10.1002/chp.47

[57] Carey, M., Buchan, H. and Sanson-Fisher, R. (2009) The Cycle of Change: Implementing Best-Evidence Clinical Practice. International Journal for Quality in Health Care, 21, 37-43. https://doi.org/10.1093/intqhc/mzn049

[58] Goodman, C., Baron, N.L., Machen, I., Stevenson, E., Evans, C., Davies, S.L., et al. (2011) Culture, Consent, Costs and Care Homes: Enabling Older People with Dementia to Participate in Research. Aging and Mental Health, 15, 475-481. http://www.ncbi.nlm.nih.gov/pubmed/21500014 https://doi.org/10.1080/13607863.2010.543659

[59] Towle, A. and Godolphin, W. (1999) Framework for Teaching and Learning Informed Shared Decision Making. British Medical Journal, 319, 766-771. https://doi.org/10.1136/bmj.319.7212.766 
[60] Shafir, A. and Rosenthal, J. (2012) Shared Decision Making: Advancing Patient-Centered Care through State and Federal Implementation. National Academy for State Health Policy.

[61] Edvardsson, D., Fetherstonhaugh, D., Nay, R. and Gibson, S. (2010) Development and Initial Testing of the Person-Centered Care Assessment Tool (P-CAT). International Psychogeriatrics, 22, 101-108.

http://www.ncbi.nlm.nih.gov/pubmed/19631005\nhttp://journals.cambridge.org/do wnload.php?file=/IPG/IPG22_01/S1041610209990688a.pdf\&code=b4d55ffe77fff3b2 74f024857fd4885c https://doi.org/10.1017/S1041610209990688

[62] Hargraves, I. and Montori, V. (2014) Decision Aids, Empowerment, and Shared Decision Making. BMJ, 349, g5811. https://doi.org/10.1136/bmj.g5811

[63] Elwyn, G., Dehlendorf, C., Epstein, R.M., Marrin, K., White, J. and Frosch, D.L. (2014) Shared Decision Making and Motivational Interviewing: Achieving Patient-Centered Care across the Spectrum of Health Care Problems. The Annals of Family Medicine, 12, 270-275. https://doi.org/10.1370/afm.1615

[64] Koh, H.K., Brach, C., Harris, L.M. and Parchman, M.L. (2013) Analysis \& Commentary: A Proposed "Health Literate Care Model" Would Constitute a Systems Approach to Improving Patients' Engagement in Care. Health Affairs, 32, 357-367. https://doi.org/10.1377/hlthaff.2012.1205

[65] Kim, S.P., Knight, S.J., Tomori, C., Colella, K.M., Schoor, R.A., Shih, L., et al. (2001) Health Literacy and Shared Decision Making for Prostate Cancer Patients with Low Socioeconomic Status. Cancer Investigation, 19, 684-691.

http://www.ncbi.nlm.nih.gov/pubmed/11577809 https://doi.org/10.1081/CNV-100106143

[66] Holmes-Rovner, M., Valade, D., Orlowski, C., Draus, C., Nabozny-Valerio, B. and Keiser, S. (2000) Implementing Shared Decision Making in Routine Practice: Barriers and Opportunities. Health Expectations, 3, 182-191. https://doi.org/10.1046/j.1369-6513.2000.00093.x

[67] Elwyn, G.J., Edwards, A., Kinnersley, P. and Grol, R. (2000) Shared Decision Making and the Concept of Equipoise: The Competences of Involving Patients in Healthcare Choices. British Journal of General Practice, 50, 892-897.

[68] Carey-Hazell, K. (2005) Improving Patient Information and Decision Making. Australian Health Consumer, 1, 21-22.

[69] Stiggelbout, A.M., Pieterse, A.H. and De Haes, J.C.J.M. (2015) Shared Decision Making: Concepts, Evidence, and Practice. Patient Education and Counseling, 98 1172-1179.

[70] Gerteis, M., Edgman-Levitan, S., Daley, J. and Delbanco, T. (1993) Through the Patient's Eyes. Jossey-Bass. 
Submit or recommend next manuscript to SCIRP and we will provide best service for you:

Accepting pre-submission inquiries through Email, Facebook, LinkedIn, Twitter, etc. A wide selection of journals (inclusive of 9 subjects, more than 200 journals)

Providing 24-hour high-quality service

User-friendly online submission system

Fair and swift peer-review system

Efficient typesetting and proofreading procedure

Display of the result of downloads and visits, as well as the number of cited articles Maximum dissemination of your research work

Submit your manuscript at: http://papersubmission.scirp.org/

Or contact ojn@scirp.org 